The question of the illumination best suited for perimeter measurements will be reserved for a later report. The question of proper colours for the perimeter is correlated with that of proper illumination. . But the committee, from a standpoint of light value, recommends the set submitted by Weiss \& Sons, of London, decided upon some years ago at the Heidelberg Congress.

\title{
Medal for Research of the American Ophthalmological Society
}

Dr. Lucien Howe, of Buffalo, has given to the American Ophthalmological Society the sum of fifteen hundred dollars, the income from which is to provide a suitable gold medal for a thesis on ophthalmology, open to candidates, whether members or not of the Society in question. The competing essays may deal with (A) an original investigation of some phase of ophthalmology, or (B) the discovery of some new method of examination or treatment of the eyes. The gift is not offered free of some:stipulations, of which the chief are : 1. That the Society shall be incorporated, a legal process that in the State of New York offers no particular difficulty; 2. That the principal be deposited in the Society's name with the Metropolitan Trust Company of New York, or some other trust company, with instructions to pay the interest annually to the treasurer of the Society; 3. That if no thesis presented during a given year is thought worthy to be awarded the medal, the interest for that year is to be added to the principal of the fund; 4 . That as the money at the disposal of the Society will thus gradually increase, the Society will be at liberty to establish two or more such prizes; 6. That if the American Ophthalmological Society gives up or forfeits its certificate of incorporation, or ceases for more than three consecutive years to hold its annual meeting, the principal shall become the property of the Section of Ophthalmology of the American Medical Association.

\section{Monument to the Memory of Brisseau}

A movement has been started in Belgium to raise a monument to the memory of Michel Brisseau, at Tournai, where he was born in 1676, and a French committee has also been formed to invite subscriptions towards the desired object; and to help in every way the work of their Belgian colleagues. Brisseau was the first to demonstrate the seat of the opacity in cataract. As readers know, he performed depression upon the eye of a dead soldier affected during life with cataract, and then opening the eye found that the opacity he had depressed into the vitreous was in fact the crystalline lens. When he placed his observation and conclusions before the 